Cahiers $d u$ MONDE RUSSE

\section{Cahiers du monde russe}

Russie - Empire russe - Union soviétique et États indépendants

$48 / 4 \mid 2007$

Varia

\title{
Anne Le Huérou, Elisabeth Sieca-Kozlowski, éds., Culture militaire et patriotisme dans la Russie d'aujourd'hui
}

\section{Amandine Regamey}

\section{(2) OpenEdition}

1 Journals

\section{Édition électronique}

URL : https://journals.openedition.org/monderusse/6107

DOI : 10.4000/monderusse. 6107

ISSN : $1777-5388$

Éditeur

Éditions de l'EHESS

\section{Édition imprimée}

Date de publication : 2 décembre 2007

Pagination : 784-787

ISBN : 978-2-7132-2148-4

ISSN : $1252-6576$

\section{Référence électronique}

Amandine Regamey, «Anne Le Huérou, Elisabeth Sieca-Kozlowski, éds., Culture militaire et patriotisme dans la Russie d'aujourd'hui », Cahiers du monde russe [En ligne], 48/4 | 2007, mis en ligne le 16 juin 2009, consulté le 02 septembre 2022. URL : http://journals.openedition.org/monderusse/ 6107 ; DOI : https://doi.org/10.4000/monderusse.6107

Ce document a été généré automatiquement le 2 septembre 2022.

Tous droits réservés 


\title{
Anne Le Huérou, Elisabeth Sieca- Kozlowski, éds., Culture militaire et patriotisme dans la Russie d'aujourd'hui
}

\author{
Amandine Regamey
}

\section{RÉFÉRENCE}

Anne LE HUÉROU, Elisabeth SIECA-KOZLOWSKI, éds., Culture militaire et patriotisme dans la Russie d'aujourd'hui. Paris : Karthala, 2008, 230 p.

1 À l'heure où les autorités russes offrent un visage de plus en plus agressif, attisant en Europe les craintes de la « menace» russe, cet ouvrage apporte une mise en perspective bienvenue sur l'utilisation politique du patriotisme en Russie et sur le lien entre culture et institutions militaires. Replaçant les deux mandats de Vladimir Putin dans le cadre de l'évolution de la Russie ces vingt dernières années, les différentes contributions montrent comment le pouvoir recourt à une rhétorique patriotique s'appuyant sur l'armée et mobilisant la population, mais soulignent néanmoins les limites de cette entreprise.

2 Comme le rappellent les éditrices dans l'introduction, le militaire constitue un aspect central d'un nouveau discours national construit autour de la fierté retrouvée. Mais le succès de cette rhétorique patriotique n'est pas absolu : l'adhésion abstraite aux valeurs militaires et à la fierté nationale n'empêche pas plus la reconnaissance du mauvais état de l'armée que le déploiement de stratégies individuelles pour échapper à la conscription.

Le premier article - mise en perspective historique des rapports entre armée et société depuis la révolution d'Octobre - est le seul à rester nettement en deçà des attentes. Manfred Sapper, sur la base d'une définition très large de la «militarisation» de la 
société, $\mathrm{y}$ inclut tour à tour, pour les besoins de la démonstration, le discours patriotique officiel, la place de l'armée dans les institutions, la politique extérieure et l'industrie, la violence sociale. On aboutit ainsi à une essentialisation des « tendances belliqueuses » ou du patriotisme de la société russe, fruit de nombreux raccourcis. L'article contraste en tout cas avec les contributions suivantes, toutes beaucoup plus précises et nuancées.

La partie sur l'armée et les institutions s'ouvre par un chapitre de Nikolaï Mitrokhine sur les relations complexes avec l'Église orthodoxe. S'intéressant aux acteurs comme aux pratiques concrètes, l'auteur montre que malgré des rapports maintenant privilégiés entre armée et Église, l'influence réelle de cette dernière reste restreinte : en témoigne l'absence d'aumôniers dans les unités militaires, en dépit des prétentions d'une l'Église toujours persuadée de son rôle historique. L'armée, dont une partie des cadres reste méfiante, se heurte de son côté à une institution soucieuse de préserver ses privilèges. Les relations en définitive se caractérisent par une déception réciproque.

On doit à Elisabeth Sieca-Kozlowski un précieux panorama détaillé de la transformation des médias militaires. La relative libéralisation du début des années 1990 conduit à la véritable défaite médiatique de l'armée lors de la première guerre de Tchétchénie. Une reprise en main progressive marque la seconde. Le but en est à la fois d'empêcher l'accès de journalistes indépendants et de mettre en place un réseau de communication efficace, tant au sein de l'armée (système « Kavkaz ») qu'à destination de l'extérieur (création du Rosinformcentr). Renforcées à l'été 2000, ces mesures culminent dans l'adoption de la doctrine de la sécurité de l'information (notion « d'abus de liberté d'information»), la recréation de médias militaires (chaîne de télévision Zvezda) et l'installation enfin de représentants des siloviki (structures de force) dans les médias.

Selon Isabelle Facon, la seconde guerre de Tchétchénie eut un impact sur l'armée même, entraînant sa réforme, sans pour autant que son poids politique en soit renforcé. À partir de 2002, la doctrine militaire est modifiée : prise en compte des menaces internes et du terrorisme; recrutement de professionnels ou de kontraktniki majoritaire au détriment des appelés; mise en place d'unités de combats plus flexibles. Même si les siloviki dominent au niveau politique - depuis 2000, les représentants du président dans les régions en sont tous issus -, l'armée perd de son poids relatif au détriment des autres structures de force : l'état-major militaire, relégué à un simple rôle d'élaboration de la stratégie, perd ses fonctions opérationnelles. Le renforcement du prestige de l'armée n'est que relatif: c'est en fait bien plus le patriotisme que l'armée elle-même qui est valorisé.

7 La seconde partie est consacrée aux relations entre armée et société. Elisabeth SiecaKozlowski se penche sur la résurgence du šefstvo, ces liens privilégiés de patronage entre les autorités locales et l'armée. Instauré dans les années 1920, quasiment disparu à la fin de la période soviétique, ilrenaît dans les années 1990, lorsque l'inflation galopante, la réduction des dépenses militaires et les détournements de fonds rendent la situation de l'armée catastrophique. Se mettent en place des réseaux plus ou moins spontanés et informels d'échange entre les autorités locales et les unités militaires, consistant essentiellement en un soutien matériel (argent, ravitaillement, vêtements) à ces dernières. Avec le second mandat de Putin et le lancement des projets patriotiques, les relations changent de logique: l'armée se pose en instigatrice du šefstvo, se proposant pour jouer un rôle éducatif, et l'aspect idéologique reprend une place fondamentale.

Stephen Webber s'interroge sur les effets de l'éducation patriotique chez les jeunes et sur les répercussions sociales des mesures officielles. Abolie en 1991, la "préparation 
militaire» pour les 15-17 ans est réintroduite dans les écoles fin 1999 et suscite en définitive peu de débats. Pour S. Webber, c'est plutôt l'insistance sur le service militaire obligatoire, avec un mélange de politique incitative et d'incorporation forcée des appelés, qui entraîne une véritable réaction de protestation des citoyens et des médias. La réduction du service militaire obligatoire à un an, la volonté proclamée de s'attaquer aux problèmes de la dedovščina, le scandale autour de l'affaire Syčev (conscrit amputé à la suite de mauvais traitements) montreraient, selon l'auteur, qu'il y a renégociation des politiques publiques en fonction des réactions sociétales. On aimerait pouvoir en être convaincu.

9 Un autre volet de l'éducation patriotique concerne la manière dont celle-ci est représentée à l'écran. David Gillespie souligne à cet égard l'importance de la «Grande Guerre patriotique », dont le traitement est quasiment constant entre les périodes soviétique et postsoviétique. Second thème central, les films sur la guerre d'Afghanistan et de Tchétchénie dépeignent un ennemi diabolisé, impitoyable, violent, mais soulignent aussi les maux de l'armée, exemplaires de ceux de la Russie, la vie des soldats gâchée par la guerre. Ce n'est que dans les plus récents qu'apparaît le personnage du super-héros russe. Les séries télévisées inspirées de la guerre de Tchétchénie placent toutes en vedette le "vrai soldat ", réhabilitant une armée qui contraste avec une Russie gangrenée par la corruption et la mafia. Bien qu'il couvre un grand nombre de films, l'article aurait sans doute gagné à s'enrichir d'une étude de la réception de ces films, voire de leur mise en perspective avec le discours politique.

10 C'est enfin avec intérêt qu'on lira dans "Militer contre les militaires" l'analyse de Françoise Daucé sur l'évolution des formes de mobilisation contre l'armée. Créées au moment de la perestroïka, les associations de mères de soldats se sont engagées tant sur les problèmes de la conscription et de la dedovščina que contre la guerre en Tchétchénie, pour la réforme de l'armée et la promotion de l'État de droit. Mais depuis 2000, accusées d'être des antipatriotes aux ordres de l'étranger, elles cherchent à se protéger et, dans le cadre d'un strict légalisme, à bénéficier d'un soutien institutionnel, en se présentant par exemple comme proches de la procurature militaire. À l'inverse, les associations gouvernementales des mères de soldat, qui tiennent un discours patriotique valorisant le service militaire, ont de leur côté de plus en plus recours aux références démocratiques et au vocabulaire des droits civiques. Voilà qui, par un véritable brouillage des repères, affaiblit plus encore les associations indépendantes et une société civile déjà sous contrôle.

11 Frédéric Charillon fait remarquer dans la préface que ce livre a l'avantage d'apporter une analyse inédite de nombreux aspects des relations armée-nation dans la Russie de Putin, et que le choix d'une approche sociologique permet non seulement d'éclairer des phénomènes peu connus, mais aussi d'explorer les multiples dimensions de ce qui constitue la puissance russe. Soulignons enfin que l'ouvrage, incontournable pour tous ceux qui travaillent sur les questions militaires ou sur les différents aspects de la politique patriotique, est également précieux pour ceux qui cherchent des clés fines de compréhension de la Russie actuelle. 